\title{
TOLERÂNCIA DO TIFToN 85 (Cynodon spp.) E DA Brachiaria brizantha AO GLYPHOSATE
}

\author{
Tifton 85 (Cynodon spp.) and Brachiaria brizantha Tolerance to Glyphosate
}

\author{
SANTOS, M.V. ${ }^{2}$, FERREIRA, F.A. ${ }^{3}$, FREITAS, F.C.L. ${ }^{4}$, IKEDA, A.K. ${ }^{5}$, OLIVEIRA, F.L.R. ${ }^{6}$, ROCHA, \\ D.C.C. ${ }^{7}$, LIMA, J.G. ${ }^{6}$, SILVA, F.N.A. ${ }^{6}$ e ASSIS, F.G.V. ${ }^{8}$
}

\begin{abstract}
RESUMO - Objetivou-se avaliar a tolerância de Tifton 85 e Brachiaria brizantha ao glyphosate e verificar o controle de $B$. brizantha em área de pastagem de Tifton 85 já estabelecida. O delineamento experimental foi em blocos casualizados, com quatro repetições, em que se testaram as doses: 0, 720, 1.440, 2.160 e $2.880 \mathrm{~g} \mathrm{ha}^{-1}$ de glyphosate. Cada parcela possuia dimensões de 3,5 $\mathrm{m}$ de comprimento por 3,0 $\mathrm{m}$ de largura, totalizando $10,5 \mathrm{~m}^{2}$, com área útil de $7,5 \mathrm{~m}^{2}$. A eficiência do herbicida no controle de $B$. brizantha e o nível de intoxicação nas plantas de Tifton 85 foram avaliados 15, 30 e 60 dias após aplicação (DAA), mediante escala de 0 a 100, em que 0 é ausência de controle e/ou intoxicação e 100, controle total ou morte das plantas. Para avaliação da produção e do potencial de rebrota das forrageiras, as plantas de ambas as espécies foram colhidas aos 300 DAA e secas em estufa. Observou-se controle acima de $90 \%$ das plantas de $B$. brizantha a partir das doses de 1.473,75 e 1.721,25 $\mathrm{g}^{-1} \mathrm{de}^{-1}$ glyphosate, aos 30 e 60 DAA, respectivamente. As porcentagens de intoxicação das plantas de Tifton 85, referente a estas doses de controle de $B$. brizantha, foram, respectivamente, de 24,90 e $4,13 \%$ aos 30 e 60 DAA. Além disso, aos 60 DAA, para a maior dose avaliada (2.880 $\mathrm{g} \mathrm{ha}^{-1}$ de glyphosate) foi observada intoxicação das plantas de Tifton 85 de apenas 18,22\%. Aos 300 DAA, observou-se ausência de produção de massa seca de B. brizantha a partir da dose de $2.160 \mathrm{~g} \mathrm{ha}^{-1}$ do herbicida, devido ao eficiente controle. Os resultados evidenciam maior tolerância das plantas de Tifton 85 ao glyphosate em relação às plantas de $B$. brizantha, possibilitando o controle desta espécie em pastagem estabelecida de Tifton 85 , sem causar danos à forrageira cultivada.
\end{abstract}

Palavras-chave: herbicida, pastagem, forrageira indesejável.

\begin{abstract}
This study aimed to evaluate Tifton 85 and Brachiaria brizantha tolerance glyphosate and verity Brachiaria brizantha control in an established Tifton 85 pasture area. Rates of 0; 720; 1.440; 2.160; and $2.880 \mathrm{~g} \mathrm{ha}^{-1}$ of glyphosate were tested in to an experiment arranged in a randomized block design, with four replicates divided into $3.5 \mathrm{~m} \times 3.0 \mathrm{~m}$, totaling $10.5 \mathrm{~m}^{2}$, and only $7.5 \mathrm{~m}^{2}$ of useful area. Herbicide efficiency in B. brizantha control and intoxication level on Tifton 85 plants were evaluated at 15, 30 and 60 days after application (DAA), following the scale from $O$ (absence of control and/or intoxication) to 100 (total control or plant death). At 300 DAA, the forage plants of both species were cut and dried to evaluate production and sprouting potential. Control superior to $90 \%$ of $\boldsymbol{B}$. brizantha plants was observed from $1,473.75$ and $1,721.25 \mathrm{~g} \mathrm{ha}^{-1}$ of glyphosate rates, respectively at 30 and $60 \mathrm{DAA}$. The intoxication of Tifton 85 plants referring to $B$. brizantha control rates were 24.90 and $4.13 \%$, respectively. At 60 DAA, 18.22\% of Tifton 85 plants intoxication was observed at the highest rate evaluated (2.880 $\mathrm{g} \mathrm{ha} \mathrm{h}^{-1}$ of glyphosate). Absence of B. brizantha dry matter production occurred at $300 \mathrm{DAA}$, at $2.160 \mathrm{~g} \mathrm{ha}^{-1}$ herbicide rate as a result of efficient control. Results showed higher tolerance of Tifton 85 plants to glyphosate in relation to $\boldsymbol{B}$. brizantha plants, allowing this species control in established Tifton 85 pasture, with no damage to the cultivated forage.
\end{abstract}

Keywords: herbicide, pasture, grass weeds

1 Recebido para publicação em 5.9.2007 e na forma revisada em 27.3.2008

2 Estudante de Doutorado em Zootecnia - UFV, < marciavitori@hotmail.com>; ${ }^{3}$ Professor Titular - UFV; ${ }^{4}$ Professor Adjunto UFERSA; ${ }^{5}$ Mestranda em Biologia Animal - UFV; ${ }^{6}$ Graduanda em Zootecnia - UFV; 7 Doutorando em Zootecnia - UFV; ${ }^{8}$ Zootecnista - UFV, Universidade Federal de Viçosa, Departamento de Fitotecnia, Viçosa - MG, CEP 36570-000. 


\section{INTRODUÇÃO}

As plantas daninhas apresentam grande capacidade de interferência, por competirem por luz, água e nutrientes, reduzindo a quantidade e qualidade da forragem produzida, além de causarem ferimentos, intoxicação e até morte dos animais (Silva et al., 2006).

Embora a maioria das espécies daninhas em pastagem sejam dicotiledôneas anuais e perenes, é comum em áreas de cultivo do gênero Cynodon a ocorrência de outras espécies forrageiras, como as do gênero Brachiaria, sendo, entretanto, indesejáveis, devido a sua grande capacidade de competir e, geralmente, dominar a forrageira de interesse, além da redução da qualidade nutricional do feno em áreas destinadas a essa produção (Santos et al., 2006).

Dentre as forrageiras do gênero Cynodon, o Tifton 85 se destaca, por ser uma gramínea perene, de crescimento prostrado, estolonífera e rizomatosa, destinada tanto para produção de feno e silagem como para pastejo (Pedreira, 1996), apresentando alto valor nutritivo, alta relação folha/colmo e alta produção.

O controle de plantas daninhas gramíneas em pastagens não é uma tarefa simples, devido à inexistência no mercado de herbicidas seletivos para as espécies forrageiras, ao grande banco de sementes do solo e à germinação irregular, além da alta capacidade de rebrota de algumas espécies (Pereira \& Campos, 2001).

Na literatura existem alguns trabalhos sobre o controle de Brachiaria em áreas de cultivo de forrageiras do gênero Cynodon. Carvalho et al. (2005) verificaram eficiência de $90 \%$ no controle de $B$. decumbens em pastagens já estabelecidas de Tifton 85 e Coast-Cross, utilizando $1.120+2.880 \mathrm{~g} \mathrm{ha}^{-1}$ de diuron + MSMA, aos 42 DAA. Essas doses causaram, segundo os autores, injúrias leves nas plantas do gênero Cynodon, não afetando o desenvolvimento dessas forrageiras após 30 DAA. Esses mesmos autores obtiveram controle ineficiente quando da utilização de $2.880 \mathrm{~g} \mathrm{ha}^{-1}$ de MSMA. Santos et al. (2006) relatam nível de intoxicação de $12,05 \%$ das plantas de Tifton 85 tratadas com $738,28 \mathrm{~g} \mathrm{ha}^{-1}$ de glyphosate, aos 60 DAA, evidenciando a diferença de tolerância dessa forrageira ao herbicida glyphosate.
Apesar de o glyphosate ser registrado como não-seletivo, apresenta-se como uma molécula promissora para controle de gramineas forrageiras em pastagem de Tifton 85, dada a maior tolerância do gênero Cynodon a esse herbicida (Santos et al., 2006; 2007), quando comparado com outras forrageiras indesejáveis.

Condições que favoreçam a fotossintese auxiliam também a translocação do glyphosate (Dellacioppa et al., 1986). A translocação representa um processo essencial para a eficácia deste herbicida (Wanamarta \& Penner, 1989). Da mesma forma, a absorção e o metabolismo também podem influenciar a suscetibilidade de uma planta ao glyphosate (Monquero et al., 2004).

Objetivou-se com este trabalho avaliar a tolerância de Tifton 85 e $B$. brizantha ao glyphosate e verificar o controle de $B$. brizantha $\mathrm{cv}$. Marandu em área de pastagem de Tifton 85 já estabelecida.

\section{MATERIAL E MÉTODOS}

O ensaio foi conduzido, de janeiro a dezembro de 2005, em pastagem já estabelecida com a forrageira Tifton 85, altamente infestada com Brachiaria brizantha cv. Marandu (Figura 1A), localizada no setor de Eqüideocultura do Departamento de Zootecnia da Universidade Federal de Viçosa, no município de Viçosa, Minas Gerais.

O delineamento experimental foi em blocos casualizados, com quatro repetições, avaliando-se cinco doses de glyphosate: 0, 720, $1.440,2.160$ e $2.880 \mathrm{~g} \mathrm{ha}^{-1}$. Cada parcela possuía dimensões de $3,5 \mathrm{~m}$ de comprimento por 3,0 $\mathrm{m}$ de largura, totalizando $10,5 \mathrm{~m}^{2}$ e área útil de $7,5 \mathrm{~m}^{2}$.

Cerca de 40 dias antes da aplicação do herbicida, as plantas de $B$. brizantha e de Tifton 85 foram roçadas e a massa verde retirada da área experimental, de modo a estimular o surgimento de novas brotações.

No momento da aplicação do glyphosate, as plantas de $B$. brizantha apresentavam-se em bom estado vegetativo, com cerca de $40 \mathrm{~cm}$ de altura, e a forrageira Tifton 85 (Cynodon spp.), com bom estande de plantas, proporcionando boa cobertura do solo (Figura 1B). A aplicação do herbicida foi realizada por meio 

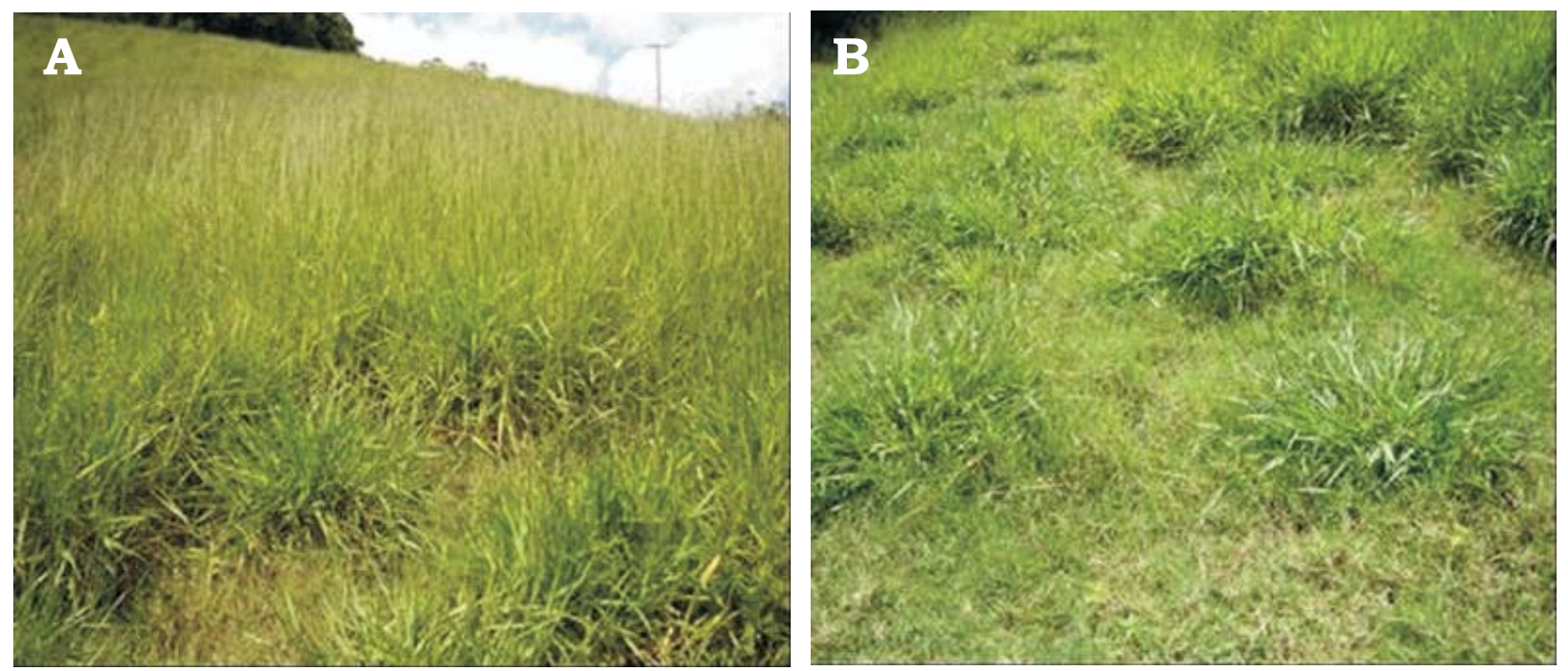

Figura 1 - Infestação da área experimental por plantas de Brachiaria brizantha (A), com bom estado vegetativo e cobertura do solo das duas forrageiras no momento da aplicação (B).

de pulverizador costal, munido de barra com dois bicos de jato plano ("leque") XR 11003, espaçados entre si de $0,5 \mathrm{~m}$, à pressão constante de $210 \mathrm{kPa}$, proporcionando volume de calda aplicado equivalente a $250 \mathrm{~L} \mathrm{ha}^{-1}$, sendo realizada no dia 18 de fevereiro nas seguintes condições ambientais: umidade relativa do ar de $82 \%$, temperatura de $27^{\circ} \mathrm{C}$, velocidade do vento de $3,0 \mathrm{~km} \mathrm{~h}^{-1}$ e solo úmido. O produto comercial utilizado foi o Roundup original, na concentração de $360 \mathrm{~g} \mathrm{~L}^{-1}$ de glyphosate. A adubação de cobertura foi realizada aos 15 dias após aplicação do herbicida (DAA), com $50 \mathrm{~kg} \mathrm{ha}^{-1}$ de N, utilizando uréia como fonte de nutriente.

A eficiência dos tratamentos no controle das plantas de $B$. brizantha e o nivel de intoxicação do Tifton 85 foram avaliados aos 15, 30 e 60 DAA, por meio de observações visuais, utilizando-se escala de 0 a 100 , em que 0 indica ausência de controle e/ou intoxicação e 100, controle total e/ou morte das plantas.

Decorridos 60 DAA, foram colhidos aleatoriamente seis rizomas de plantas submetidas à maior dose do glyphosate $\left(2.880 \mathrm{~g} \mathrm{ha}^{-1}\right)$ e de plantas não submetidas ao herbicida $\left(0 \mathrm{~g} \mathrm{ha}^{-1}\right.$ = testemunha). Os rizomas foram imediatamente fixados em FAA50 por 24 horas (Johansen, 1940), dentro de frascos, que foram colocados em dessecador submetido a vácuo. Após a fixação, o material foi estocado em etanol $70 \%$. Cortes transversais dos rizomas foram obtidos em micrótomo de mesa, sendo posteriormente submetidos ao reagente Lugol, para verificação da presença de amido; as lâminas foram montadas em glicerina + água 1:1 (Johansen, 1940). As observações e ilustrações foram obtidas em fotomicroscópio Olimpus AX 70 com sistema U - Photo, pertencente ao Laboratório de Anatomia do Departamento de Biologia Vegetal da Universidade Federal de Viçosa.

A produtividade e a capacidade de rebrota das plantas de Tifton 85 e $B$. brizantha foram avaliadas tomando-se como base a produção de biomassa seca das plantas, realizada aos 300 DAA, por meio de duas amostragens de $0,25 \mathrm{~m}^{2}$ por unidade experimental. Para isso, as plantas foram colhidas e separadas por espécie e levadas à estufa com circulação forçada de ar, à temperatura de $70 \pm 3{ }^{\circ} \mathrm{C}$, até peso constante. A amostragem para $B$. brizantha foi realizada levando-se em conta apenas as plantas rebrotadas e/ou remanescentes submetidas aos tratamentos, não considerando, dessa forma, as plantas germinadas após a aplicação.

Os resultados foram submetidos às análises de variância, pelo teste $\mathrm{F}$ a $5 \%$ de probabilidade. Foram ajustadas equações de regressão em função das doses aplicadas, para os dados de controle de $B$. brizantha e intoxicação de Tifton 85, e teste de comparação de médias, 
para os dados de matéria seca de ambas as espécies estudadas, por meio do teste de Duncan (5\%).

\section{RESULTADOS E DISCUSSÃO}

A eficiência do glyphosate no controle de plantas de $B$. brizantha e na intoxicação das plantas de Tifton 85 foi influenciada pelas doses utilizadas $(\mathrm{P}<0,05)$. Observou-se controle de $B$. brizantha acima de $90 \%$ aos 30 e 60 DAA, a partir das concentrações de $1.473,75$ e $1.721,25 \mathrm{~g} \mathrm{ha}^{-1}$ de glyphosate, respectivamente (Figura 2). Aos 15 DAA, foi observado controle máximo de $74,78 \%$ na dose de $2.880 \mathrm{~g} \mathrm{ha}^{-1} \mathrm{de}$ glyphosate.

….. $\left.\hat{\mathrm{Y}}={ }_{15 \mathrm{DAA}}=73,31 /(1+\exp (-(\mathrm{x}-1028,79) / 475,54)) ; \mathrm{R}^{2}=0,98\right)$

$\left.-\hat{Y}={ }_{30 D A A}=98,51 /(1+\exp (-(x-936,40) / 225,40)) ; R^{2}=0,99\right)$

$\left.-\cdots \hat{Y}={ }_{600 \mathrm{AA}}=99,45 /(1+\exp (-(x-1134,73) / 253,05)) ; R^{2}=0,99\right)$

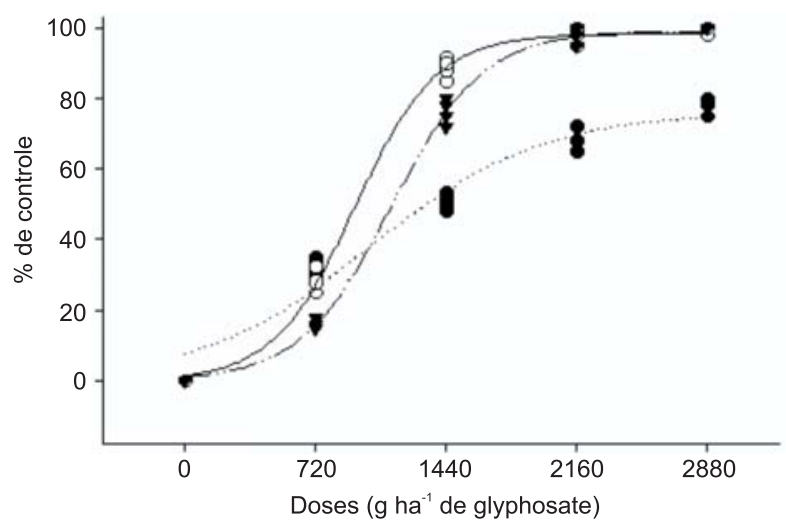

Figura 2 - Controle de Brachiaria brizantha aos 15, 30 e 60 dias após a aplicação, em função das doses de glyphosate.

Os resultados são semelhantes aos descritos por Pires (1998), que relata 100\% de controle de $B$. brizantha, aos 30 DAA, com utilização de $1.440 \mathrm{~g} \mathrm{ha}^{-1}$ de glyphosate. Werlang et al. (2003) obtiveram controle de $80 \%$ de $B$. decumbens aos $21 \mathrm{DAA}$, com $1.440 \mathrm{~g} \mathrm{ha}^{-1} \mathrm{de}$ glyphosate nas formulações WG e Transorb.

Os sintomas de intoxicação do Tifton 85 ao glyphosate, caracterizados por cloroses, necroses e morte do ápice foliar, se intensificaram com o aumento das doses utilizadas, sendo semelhantes aos descritos por Roman et al. (2004) e Santos et al. (2006). Quanto à tolerância do Tifton 85 ao glyphosate, embora os sintomas observados nas plantas de Tifton 85, para doses superiores a $2.160 \mathrm{~g} \mathrm{ha}^{-1}$, tenham sido mais intensos e precoces, ocasionando redução na produção, isso não foi o suficiente para causar a morte dessa forrageira.

As doses efetivas no controle de $B$. brizantha foram relativamente mais altas, quando em comparação àquelas observadas por Santos et al. (2006), que cultivaram essas duas forrageiras em vasos e com aplicação do glyphosate no inverno. Os resultados encontrados por esses autores foram: 892,97 e 738,28 $\mathrm{g} \mathrm{ha}^{-1}$ de glyphosate no controle de $B$. brizantha aos 30 e 60 DAA. O requerimento de doses mais elevadas, em pastagem já estabelecida, devese possivelmente ao maior sistema radicular e à época de aplicação do herbicida. As plantas de Tifton 85 tendem a apresentar no verão maior tolerância ao herbicida glyphosate, em razão, possivelmente, das condições favoráveis ao crescimento e desenvolvimento, o que pode estar relacionado à maior facilidade de metabolização, conjugação e/ou exsudação do herbicida pelas plantas, além do maior desenvolvimento de rizomas ricos em amido, servindo de reservas para recuperação das plantas.

Porcentagens de intoxicação das plantas de Tifton 85, obtidas aos 30 e 60 DAA, referentes às doses de controle de $B$. brizantha foram, respectivamente, de 24,90 e $4,13 \%$. Além disso, as 60 DAA, para a maior dose avaliada (2.880 $\mathrm{g} \mathrm{ha}^{-1}$ de glyphosate) foi observado nivel de intoxicação das plantas de Tifton 85 de $18,22 \%$ (Figura 3). A baixa intoxicação do Tifton 85 evidencia a maior tolerância dessa forrageira ao glyphosate, quando comparado a $B$. brizantha (Figuras 2 e 3 ).

As Figuras 4 e 5 ilustram os efeitos do herbicida no controle de $B$. brizantha e no desenvolvimento de Tifton 85 (Cynodon spp.), aos 30 e 60 dias após aplicação do glyphosate.

Os valores de massa seca variaram entre as diferentes doses testadas $(\mathrm{P}<0,05)$, aos 300 DAA (Tabela 1). Neste período, observouse redução na produção de massa seca de $B$. brizantha com o aumento das doses de glyphosate aplicadas, quando comparado à testemunha, com ausência de produção de massa seca a partir da dose de $2.160 \mathrm{~g} \mathrm{ha}^{-1}$ do herbicida, devido ao eficiente controle dessa espécie. O controle das plantas de $B$. brizantha possibilitou aumento na produção de Tifton 85 , 


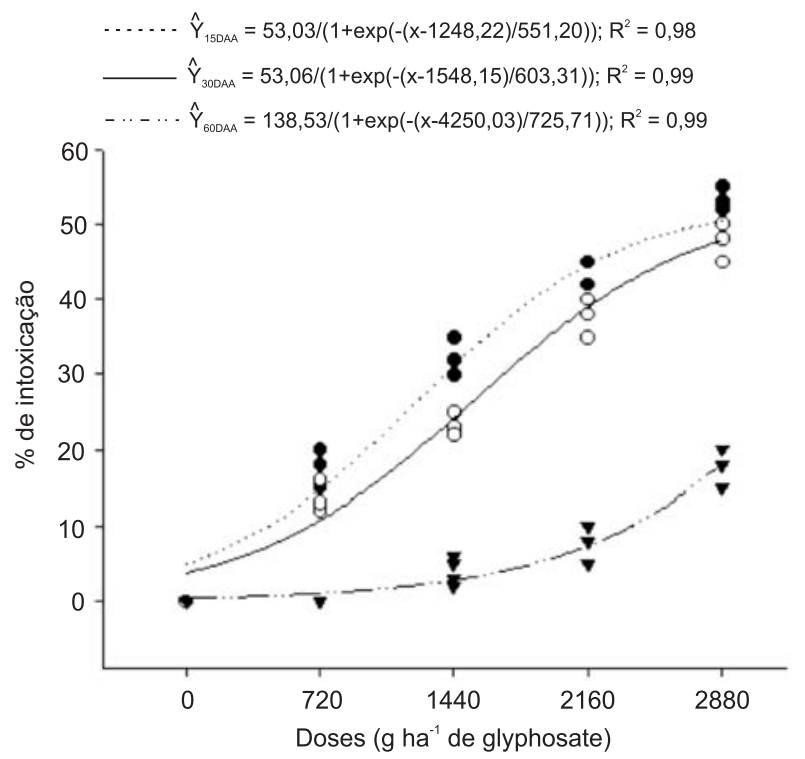

Figura 3 - Intoxicação das plantas de Cynodon spp. (Tifton $85)$ aos 15, 30 e 60 dias após a aplicação, em função das doses de glyphosate.

alcançando um máximo quando da aplicação de $2.160 \mathrm{~g} \mathrm{ha}^{-1}$ de glyphosate. A partir dessa dose houve decréscimo da produção de massa seca em razão da maior intoxicação das plantas de Tifton 85, acarretando queda no crescimento e desenvolvimento dessa forrageira. Todavia, não foi verificada morte das plantas de Tifton 85. Observou-se ainda que, mesmo na maior dose aplicada, a produção forrageira é maior que a da testemunha sem controle, devido à não-interferência causada pelas plantas de $B$. brizantha (Tabela 1 ).

A maior tolerância do Tifton 85 ao glyphosate pode estar relacionada à presença de amido nos rizomas, o que foi constatado pela observação anatômica dessas estruturas (Figura 6). Essa reserva de energia pode estar suprindo as exigências das plantas tratadas com o herbicida e possibilitando sua recuperação. Segundo Machado et al. (2008), os rizomas de Digitaria insularis são também ricos em amido, dificultando possivelmente a translocação do herbicida nessas estruturas e constituindo uma fonte de reserva para sobrevivência dessas plantas, permitindo rápida brotação das gemas nos estolões. Tuffi Santos et al. (2004), estudando Commelina diffusa e Commelina benghalensis, verificaram que a tolerância ao herbicida glyphosate era maior na primeira devido à maior quantidade de amido encontrado no caule, quando comparada a $C$. benghalensis.

Devido ao grande banco de sementes no solo, à germinação irregular e à inexistência de efeito residual do glyphosate, observou-se, aos 300 DAA, presença de novas plantas de $B$. brizantha provenientes de sementes. Fazse necessária, então, a reaplicação de glyphosate, evitando a reinfestação dessas plantas na área. Segundo Santos et al. (2007), em áreas de Tifton 85, a aplicação de 133,60 e $365,63 \mathrm{~g} \mathrm{ha}^{-1}$ de glyphosate é eficiente no controle de plantas de $B$. brizantha antes do perfilhamento e com quatro a cinco perfilhos, respectivamente. Deve-se ter maior atenção ainda no caso de pastagens para eqüinos infestadas $\operatorname{com} B$. brizantha, devido à maior preferência alimentar desses animais pelo Tifton.

Associado ao manejo químico, é fundamental o manejo cultural dos pastos, objetivando propiciar condições favoráveis à forrageira cultivada, a fim de que esta possa ter capacidade competitiva com a espécie infestante. Dessa forma, o produtor deve se conscientizar da importância do uso da adubação de manutenção, da correta taxa de lotação e da disponibilidade de forragem, visando, assim, a sustentabilidade da produção forrageira.

É possível utilizar o glyphosate para controle de $B$. brizantha em pastagem já estabelecida de Tifton 85 , em razão da maior tolerância dessa espécie ao herbicida em relação a $B$. brizantha. No entanto, deve-se ficar atento à reinfestação das plantas de $B$. brizantha na área, necessitando, nesse caso, da reaplicação de subdoses do produto para total eficiência no controle. 

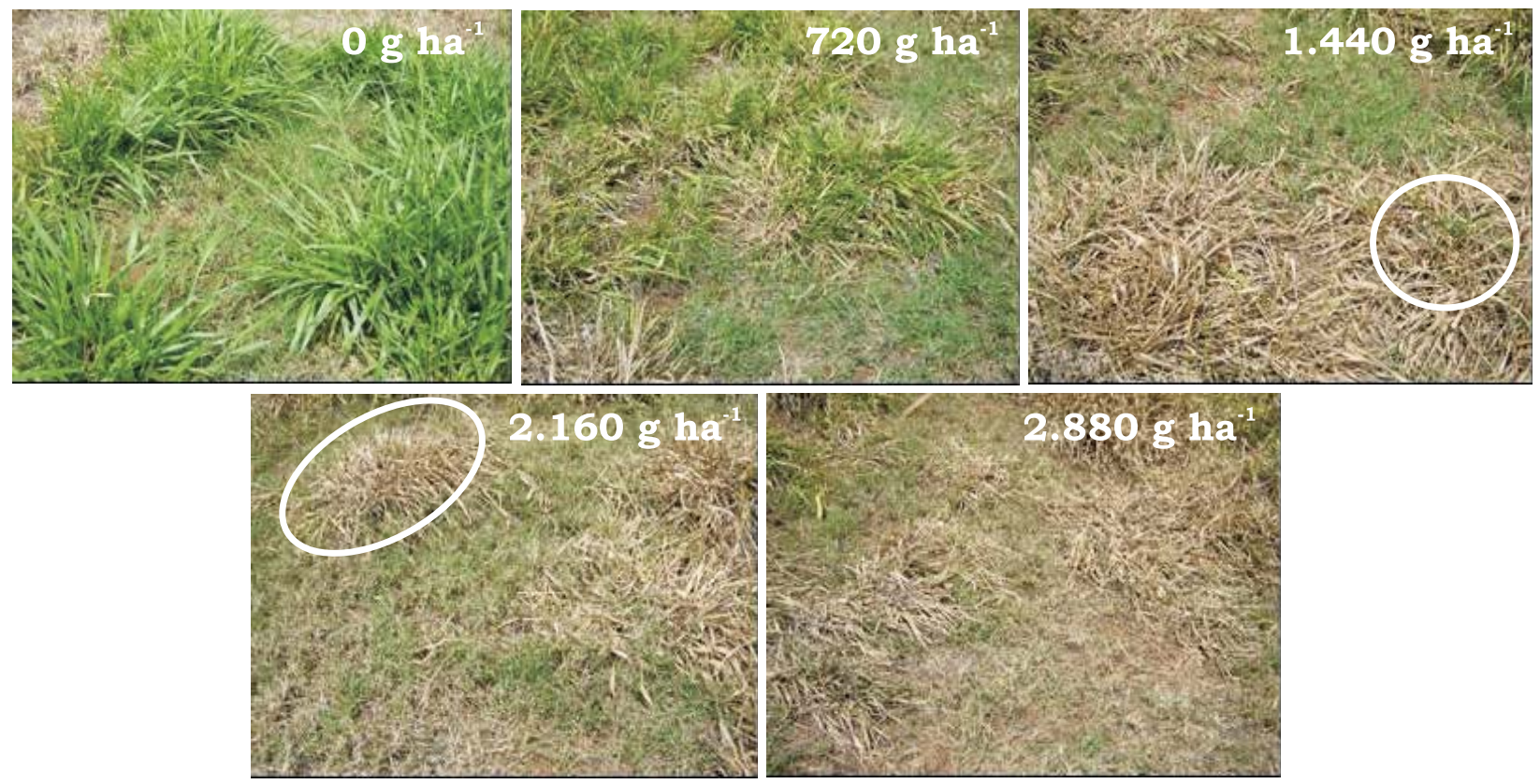

Figura 4 - Efeito do glyphosate no controle de Brachiaria brizantha e no desenvolvimento de Tifton 85 (Cynodon spp.), aos 30 dias após a aplicação, nas doses de 0 (A), 720 (B), 1.440 (C), 2.160 (D) e 2.880 (E) g ha ${ }^{-1}$, detalhe da rebrota de $B$. brizantha submetida a $1.440 \mathrm{~g} \mathrm{ha}^{-1}$ de glyphosate e ausência de rebrota com $2.160 \mathrm{~g} \mathrm{ha}^{-1}$ de glyphosate (círculos).
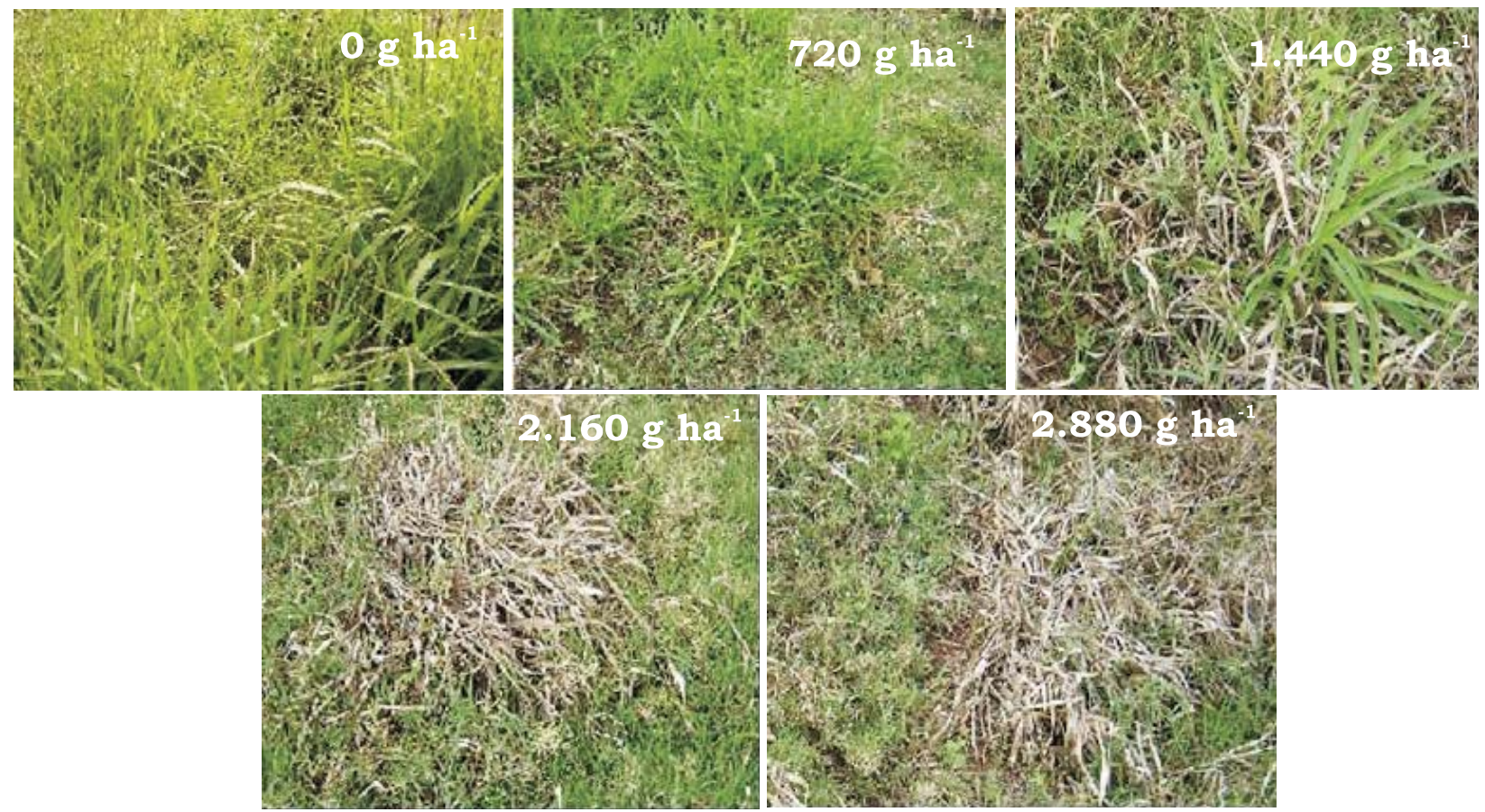

Figura 5 - Efeito do glyphosate no controle de Brachiaria brizantha e no desenvolvimento de Tifton 85 (Cynodon spp.), aos 60 dias após a aplicação, nas doses de 0 (A), 720 (B), 1.440 (C), 2.160 (D) e 2.880 (E) g ha ${ }^{-1}$; detalhe da rebrota de $B$. brizantha submetida a $1.440 \mathrm{~g} \mathrm{ha}^{-1}$ de glyphosate e ausência de rebrota com $2.160 \mathrm{~g} \mathrm{ha}^{-1}$ de glyphosate. 
Tabela 1 - Massa seca de plantas de forrageira, Tifton 85 e Brachiaria brizantha, submetidas às doses de glyphosate, 300 dias após aplicação

\begin{tabular}{|c|c|c|}
\hline \multirow{3}{*}{$\begin{array}{l}\text { Dose de glyphosate } \\
\qquad\left(\mathrm{g} \mathrm{ha}^{-1}\right)\end{array}$} & \multicolumn{2}{|c|}{300 DAA } \\
\hline & Tifton 85 & Brachiaria brizantha \\
\hline & \multicolumn{2}{|c|}{ Massa Seca $\left(\mathrm{gm}^{-2}\right)^{*}$} \\
\hline 0 (Testemunha) & $192,00 \mathrm{c}$ & $681,52 \mathrm{a}$ \\
\hline 720 & $207,00 \mathrm{c}$ & $591,00 \mathrm{~b}$ \\
\hline 1.440 & $295,20 \mathrm{~b}$ & $464,00 \mathrm{c}$ \\
\hline 2.160 & $422,20 \mathrm{a}$ & $0,00 \mathrm{~d}$ \\
\hline 2.880 & $284,80 \mathrm{~b}$ & $0,00 \mathrm{~d}$ \\
\hline $\mathrm{CV}(\%)$ & 16,48 & 12,97 \\
\hline
\end{tabular}

* Médias seguidas pelas mesmas letras na coluna não diferem entre si pelo teste de Duncan a 5\% de probabilidade.

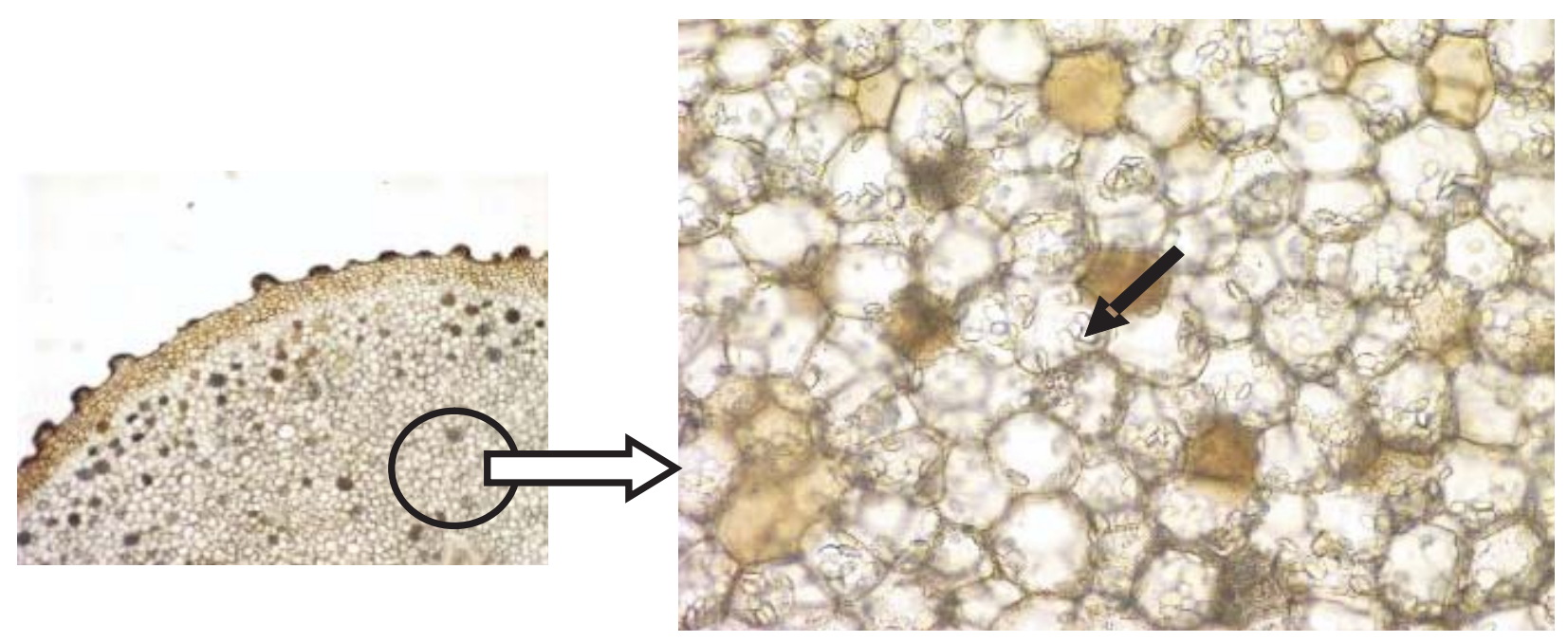

Figura 6 - Detalhe dos amiloplastos (seta), contendo grânulos de amido, em rizomas de Tifton 85.

\section{LITERATURA CITADA}

CARVALHO, J. A. et al. Controle químico de Brachiaria decumbens em pastagem de Cynodon dactylon híbridos Coast-cross e Tifton 85. R. Bras. Herbic., n. 1, p. 105-111, 2005.

DELLACIOPPA, G. et al. Translocation of the precursor of 5-enolpyruvylshikimate-3-phosphate synthase into chloroplasts of higher plants in vitro. Proc. National Acad. Sci. USA, v. 83, p. 6973-6977, 1986.

JOHANSEN, D. A. Plant microtechinique. New York: Macgraw-Hill, 1940. 523p

MACHADO, A. F. L. et al. Caracterização anatômica da folha do colmo e do rizoma de Digitaria insularis. Planta Daninha, v. 2, n. 1, 2008
MONQUERO, P. A. et al. Absorção, translocação e metabolismo do glyphosate por plantas tolerantes e susceptíveis a este herbicida. Planta Daninha, v. 22, n. 3, p. $445-451,2004$.

PEDREIRA, C. G. S. Avaliação de novas gramíneas do gênero Cynodon para a pecuária do sudeste dos Estados Unidos. In: WORKSHOP SOBRE O POTENCIAL FORRAGEIRO DO GÊNERO Cynodon, 1996, Juiz de Fora. Anais... Juiz de Fora: Embrapa-CNPGL, 1996. p. 111125.

PEREIRA, J. R.; CAMPOS, A. T. Controle da braquiária como invasora. Instrução técnica para o produtor de leite. Juiz de Fora: Embrapa Gado de Leite, 2001

PIRES, N. M. Efeitos do glyphosate e do sulfosate após a simulação de chuva em plantas de Brachiaria brizantha Stapf, submetidas ao estresse hídrico. 1998, 100 f. Tese (Doutorado em Fitotecnia) - Universidade Federal de Viçosa, Viçosa, MG, 1998.

Planta Daninha, Viçosa-MG, v. 26, n. 2, p. 353-360, 2008 
ROMAN, E. S. et al. Influência do orvalho e volume de calda de aplicação na eficácia do glyphosate na dessecação de Brachiaria plantaginea. Planta Daninha, v. 22, n. 3, p. 479-482, 2004

SANTOS, M. V. et al. Controle de Brachiaria brizantha, com uso do glyphosate, após o estabelecimento de Tifton 85 (Cynodon spp.). Planta Daninha, v. 24, n. 4, p. 813-819, 2006.

SANTOS, M. V. et al. Controle de Brachiaria brizantha, com uso do glyphosate, na formação de pastagem de Tifton 85 (Cynodon spp.). Planta Daninha, v. 25, n. 1, p. 149$155,2007$.

SILVA, A. A. et al. Biologia e controle de plantas daninhas. Viçosa, MG: Universidade Federal de Viçosa, 2006. CD-ROM
SILVA, A. A.; WERLANG, R. C.; FERREIRA, L. R Controle de plantas daninhas em pastagens. In: OBEID J. A. et al. SIMPÓSIO SOBRE MANEJO ESTRATÉGICO DA PASTAGEM. Viçosa-MG: 2002. p. 279-310.

TUFFI SANTOS, L. D. et al. Efeito do glyphosate sobre a morfoanatomia das folhas e do caule de Commelina diffusa e C. benghalensis. Planta Daninha, v. 22, n. 1, p.101-108, 2004.

WANAMARTA, G. D.; PENNER, D. Foliar absorption of herbicides. Weed Sci., v. 4, p. 215-231, 1989

WERLANG, R. C. I. et al. Efeitos da chuva na eficiência de formulações e doses de glyphosate no controle de Brachiaria decumbens. Planta Daninha, v. 21, n. 1, p. 121-130, 2003. 